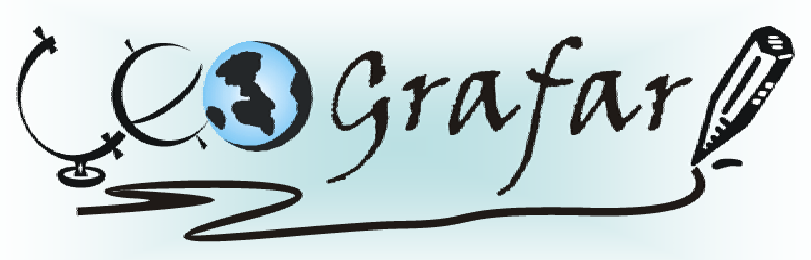

Revista Eletrônica do Programa de Pós-Graduação em Geografia - UFPR

\title{
LEVANTAMENTO DAS ÁREAS POTENCIAIS À EROSÃO LAMINAR COMO SUPORTE À DETECÇÃO DAS ÁREAS-FONTE AO ASSOREAMENTO NA BARRAGEM PIRAQUARA I ${ }^{1}$
}

\author{
LEANDRO JOSÉ RIBEIRO GUIMARÃES ${ }^{2}$; LEONARDO JOSÉ CORDEIRO SANTOS ${ }^{3}$
}

RESUMO - A barragem Piraquara I abastece parte considerável da cidade de Curitiba e Região Metropolitana. A tendência de crescimento da população a ser atendida por esta barragem indica a necessidade de preservação da qualidade da água distribuída a seus habitantes. Uma vez que as bacias hidrográficas são naturais contribuidoras de sedimentos em reservatórios, procurou-se levantar as principais áreas-fonte potenciais ao assoreamento na barragem Piraquara I. Em função de uma visão sistêmica das bacias hidrográficas e das interações entre os processos físicos e humanos que a compreendem, a metodologia deste estudo procurou integrar as características pedológicas, do relevo e uso e ocupação do solo para o diagnóstico do potencial erosivo laminar. A erosão laminar é raramente detectada nos estágios iniciais, quando o fluxo de água concentrado a escorre e começa acelerar, provocando o deslocamento das partículas do solo. Quando esses processos erosivos são identificados ainda no início, a recuperação das áreas ainda pode ser facilmente alcançada, ao evitar que o depósito de sedimentos (assoreamento) ocorra a partir do fluxo de transporte destas partículas pelos cursos fluviais, preservando e mantendo, desta maneira, a quantidade e qualidade do abastecimento de água. Algumas áreas apontam para uma preocupação no sentido de preservação, em virtude do alto potencial ao assoreamento na barragem Piraquara I.

Palavras-chave: Piraquara I, Erosão, Assoreamento, Barragem.

\section{SURVEY OF POTENCIAL LAMINAR EROSION AREAS IN ORDER TO DETECT SILTING SOURCE-AREAS IN PIRAQUARA I}

\begin{abstract}
Piraquara I barrage supplies considerable part of Curitiba and its Metropolitan area. The tendency of population's growth supplied by water from this barrage shows the necessity of water's quality preservation to the populations that need to receive this water by supplier's companies. The tributaries rivers from these hydrographical basins of Piraquara I are naturally source-areas of silting to this barrage. Based on this fact, it was detected the main source-areas to silting process in Piraquara I. An integrated vision for understanding of hydrographical basins and the physical and human process associated, this work tried to integrate elements like declivity, pedology and the soil use and occupation in order to diagnose different classes of potential laminar erosion. Laminar erosion is rarely detected in its initial stages, when the concentrated water flow starts to accelerate, removing and detaching soil particles. When these erosive processes are identified in the beginning, the recuperation of areas is possible, avoiding this way the sediment deposits (silting) in function of the flow transport of particles of soil by hydrographical basins contributors, preserving and maintaining the quantity and quality of water supply. Some areas claims for the necessity of preservation, based in high potential levels of silting in Piraquara I.
\end{abstract}

Key-words: Piraquara I, Erosion, Silting, Barrage

\footnotetext{
${ }^{1}$ Este artigo é parte integrante de Dissertação de Mestrado apresentada ao curso de Pós-Graduação do Departamento de Geografia da Universidade Federal do Paraná, 2008

${ }^{2}$ Mestre em Geografia, UFPR - e-mail: leandrojrguimaraes@hotmail.com

${ }^{3}$ Professor Doutor do Departamento de Geografia da UFPR - e-mail: santos@ufpr.br
} 


\section{INTRODUÇÃO}

Diversos estudos estão sendo desenvolvidos para definir a capacidade de abastecimento de água da Região Metropolitana de Curitiba (RMC), principalmente em função do elevado crescimento populacional registrado na RMC nas ultimas décadas e a conseqüente preocupação para o abastecimento da população. Para Andreoli et al. (2000) a análise de alguns cenários de disponibilidade hídrica dos mananciais da RMC para os próximos 50 anos foram traçados. No cenário de manutenção da disponibilidade hídrica atual, os mananciais disponíveis serão suficientes até o ano 2050 para o crescimento mínimo populacional e até o ano de 2040 para o máximo. Em condições de ausência de programas efetivos de conservação, os mananciais acima referidos estariam esgotados entre os anos de 2030 e 2035 para o máximo crescimento populacional, e entre 2035 e 2040 para as projeções de mínimo crescimento populacional.

Recentemente, diversas pesquisas indicam um elevado aumento da população da Região Metropolitana de Curitiba. Para Andreoli et al. (2000), a demanda de água prevista para o ano de 2020 foi calculada em 12,74 m³/s. Quase 50\% da disponibilização da demanda de água da RMC (que é da ordem de 7200 L/s) provém de reservatórios localizados apenas no município de Piraquara, sendo que o reservatório Piraquara I abastece mais de 8\% da população da RMC (PREFEITURA MUNICIPAL DE PIRAQUARA, 2006).

Em reservatórios, processos erosivos de bacias hidrográficas contribuintes pode originar diversos mecanismos de assoreamento, fato que colabora tanto para a diminuição da quantidade como da qualidade dos recursos hídricos. Para autores como Oliveira (1994), em referência ao levantamento dos impactos causados ao meio ambiente levantados pela Agência de Proteção Ambiental dos Estados Unidos (EPA), alguns dos principais problemas associados aos assoreamentos são: diminuição do armazenamento de água, colmatação total de pequenos lagos e açudes, destruição de habitats aquáticos, obstrução de canais de cursos d’água, elevação de turbidez, reduzindo o potencial de utilização da água e reduzindo a atividade de fotossíntese, queda da qualidade da água para o consumo humano, crescimento dos custos para o tratamento da água, veiculação de poluentes, tais como: fertilizantes, pesticidas, propagação de agentes transmissores de doenças, vírus e bactérias e obstrução de canais de irrigação e navegação.

Diversos estudos destacam o levantamento das relações entre erosão e assoreamento. Levantamentos realizados por Dias et al. (2005) indicam que a erosão e o transporte de 
sedimentos em bacias hidrográficas é um fenômeno dinâmico sujeito a alterações diversas, das quais a ação antrópica exerce grande influência. Segundo os mesmos autores, o comportamento hidrológico de bacias hidrográficas em condições de corte raso da cobertura florestal, como é o caso de grande parte da bacia de contribuição da represa de Paraibuna, causa um aumento significativo do volume de vazão, redução do tempo de pico, aumento das áreas de saturação e conseqüente potencialização do escoamento superficial, que pode levar ao assoreamento. A deposição de sedimento no reservatório é a última etapa de um processo que se inicia na erosão superficial da bacia hidrográfica. Todo o material erodido da bacia não é lançado diretamente no leito do rio, uma parte pode ficar retida em depressões naturais ou ainda ser interceptada pela vegetação ou obstáculos existentes.

De acordo com Morris e $\operatorname{Fan}^{4}$ e Carvalho $^{5}$ (1997, 2000, in: CABRAL, 2005) os impactos do assoreamento com o passar do tempo se tornam mais severos e mais fáceis de serem constatados, mas de difícil solução. São esperadas conseqüências tanto a montante quanto à jusante dos cursos d’água. A água limpa escoada para jusante da barragem tem um maior poder de erodir margens e leitos do canal de escoamento (Carvalho, 1994). Coiado ${ }^{6}$ (2001, p. 395) também aborda essa questão salientando que "à jusante da barragem, tem-se como conseqüência principal, o aumento da erosão devido ao desequilíbrio provocado pela retirada da carga natural de sedimentos do escoamento.”

Portanto, o estudo das áreas potenciais à deposição de sedimentos associados à erosão laminar na barragem Piraquara I (Figura 1) é de suma importância, por ser este tipo de erosão o ponto de partida de todo o processo erosivo. A erosão laminar é raramente detectada nos estágios iniciais, quando o fluxo de água concentrado escorre e provoca o deslocamento das partículas do solo. Quando esses processos erosivos são identificados ainda no início, a recuperação das áreas ainda pode ser facilmente alcançada, ao evitar que o depósito de sedimentos (assoreamento) ocorra a partir do fluxo de transporte destas partículas pelos cursos fluviais, preservando e mantendo, assim, a quantidade e qualidade do abastecimento de água (GUERRA et al., 1999).

Assim sendo, o objetivo geral deste estudo consiste em identificar as áreas potenciais à erosão laminar da barragem Piraquara I - que, por sua vez, dão suporte para a detecção das

\footnotetext{
${ }^{4}$ MORRIS, G. L; FAN, J. Reservoir sedimentation handbook. New York: Mcgraw-HILL, 1997.

${ }^{5}$ CARVALHO, N.O. Assoreamento de reservatórios - conseqüências e mitigação dos efeitos. In: Encontro Nacional de engenharia de Sedimentos, 4, 2000. Santa Maria. Cd rom. 1. 2000

${ }^{6}$ COIADO, E. M. Assoreamento de Reservatórios. In: Paiva J.B.D.; Paiva E.M.C.D. (Orgs.). Hidrologia Aplicada à Gestão de Pequenas Bacias Hidrográficas. Porto Alegre: ABRH, 2001. p.395.
} 
principais áreas-fonte ao assoreamento. É necessário, portanto, um diagnóstico profundo da região em estudo, como a elaboração e cruzamento de mapas plani-altimétrico, de declividade, de pedologia, de classes de erodibilidade, de suscetibilidade à erosão laminar, de cobertura vegetal e uso do solo.

FIGURA 1 - LOCALIZAÇÃO GEOGRÁFICA DA ÁREA DE ESTUDO

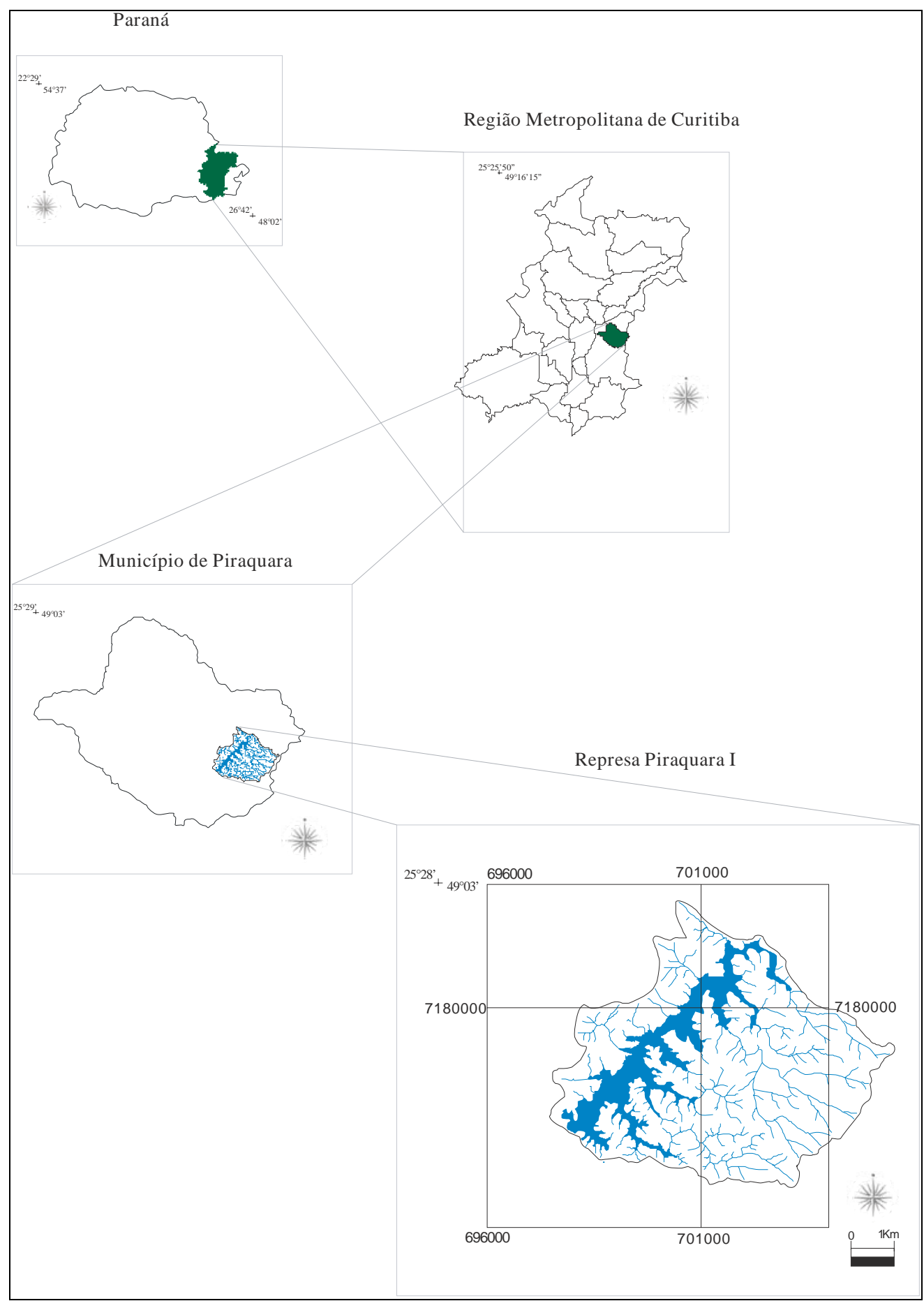




\section{PROCEDIMENTOS METODOLÓGICOS}

A metodologia a seguir foi adaptada de Salomão (1994) para a detecção do potencial erosivo. Esta foi desenvolvida a partir de levantamentos dos principais fatores naturais que geram os processos erosivos e das formas antrópicas de uso e ocupação do solo na formação da erosão laminar.

O quadro 1 apresenta as principais etapas dos procedimentos metodológicos adotados.

QUADRO 1 - ESQUEMA DOS PROCEDIMENTOS METODOLÓGICOS ADOTADOS

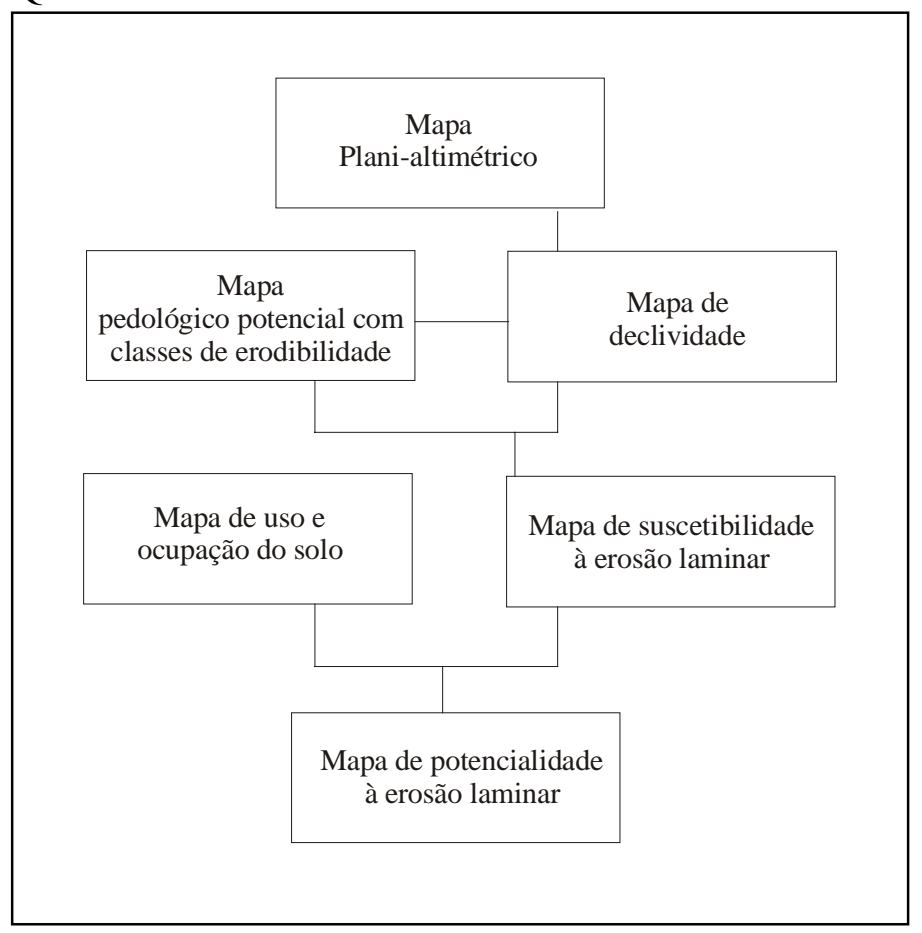

O mapa pedológico (figura 2) foi realizado a partir do mapa de declividade. Os demais fatores formadores do solo, descritos por Jenny (1941) como clima, geologia, tempo e organismos não foram utilizados como parâmetros em função da limitação da extensão da bacia - que, por ser pequena $\left(25,16 \mathrm{~km}^{2}\right)$, não sofre influências significativas dos fatores não levantados. As categorias de solos existentes foram adaptadas de Salomão (1994, in: GUERRA et al., 1999), conforme o quadro 2:

QUADRO 2- GRAUS DE DECLIVIDADE E TIPOS DE SOLO ASSOCIADOS

\begin{tabular}{|c|c|}
\hline Declividade (em \%) & Solo associado \\
\hline$>20$ & Cambissolo - Litossolo; \\
\hline 12 a 20 & Argissolo; \\
\hline De 0 a 12 & Latossolo; \\
\hline
\end{tabular}

Fonte: adaptado de Salomão (1994, in: GUERRA et al., 1999) 
Não foi elaborado no presente estudo um mapa a partir das produções cartográficas pedológicas existentes na área de estudo, em função da problemática da distorção de escala dos mapas existentes (no caso, mapa de Solos em escala 1:600.000 da Embrapa). Incluem-se ainda no mapa pedológico elaborado os Gleissolos. Os limites destes foram estipulados a partir dos espaçamentos das curvas de nível próximas das redes de drenagem. A definição de critérios em quais porções do relevo estes solos se situam são fundamentais também para a estipulação dos limites. Lima (2004) identificou em porções entre 0 e 5\% de declividade nas porções de relevo plano, em fundos de vale.

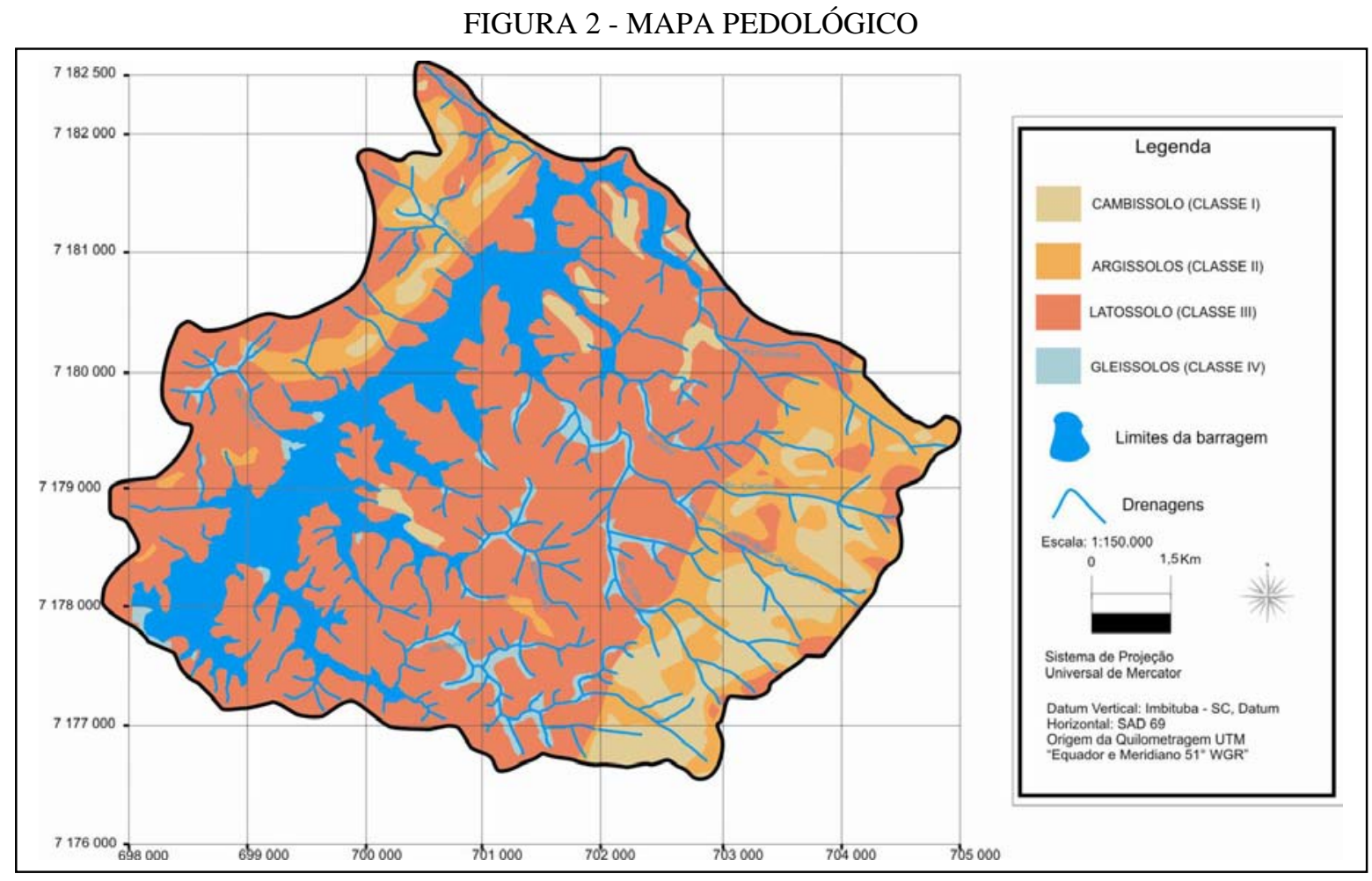

A partir das unidades pedológicas levantadas as classes de erodibilidade são foram definidas. Para Silva (2007), a erodibilidade é a característica do solo que corresponde à sua suscetibilidade à erosão. Pode ser definida como a quantidade de material que é removido por unidade de área quando os fatores determinantes da erosão permanecem constantes.

As respectivas categorias de classes de erodibilidade foram utilizadas a partir das definições de Salomão (1994, In: GUERRA et al., 1999). As classes adotadas, representadas na figura 2, partem de um grau maior de erodibilidade (associado aos Cambissolos, por exemplo) até um grau menor (Gleissolos). Certos fatores justificam a inclusão dos solos nas categorias de classes de erodibilidade. Os Cambissolos, cuja textura é variável entre arenosa e silto-argilosa, são solos extremamente sensíveis a processos erosivos, dado, sobretudo a sua 
impermeabilidade e características físicas. Os Argissolos apresentam distinta individualização de horizontes, com espessuras geralmente inferiores aos latossolos e caracterizam-se pela textura argilosa e média, são bem drenados e moderadamente porosos, sobretudo na parte superficial. Estão normalmente associados a matas de galeria, no curso superior das drenagens, onde o relevo vai do plano ao suave ondulado, sendo assim não tão erodíveis quanto os Cambissolos (Guerra, 1999).

Os Latossolos são solos maduros, com horizontes profundos e bem delimitados. Por essa razão, são também fortemente lixiviados, isto é, pobres em nutrientes. São constituídos basicamente de grão de quartzo, na fração areia; e argilas inertes, tipo caolinita, e óxidos de ferro, na fração argila. Por serem inertes e pela grande coesão natural, são extremamente estáveis e resistentes a processos erosivos. A alta permeabilidade desses solos permite, com raras exceções, uma boa capacidade de infiltração. Os macroporos existentes nos Latossolos, formados por mecanismos que agregam os óxidos de ferro e as argilas, são os responsáveis por essa permeabilidade. São responsáveis, também, pela alta transmissividade, a qual permite a livre circulação da água freática, que abastece as nascentes que drenam para o vale dos córregos. Essa característica é constante, seja em latossolos de textura média, seja em de textura argilosa. No que concerne à vulnerabilidade à erosão, se mantidas suas características físicas e a cobertura vegetal, os Latossolos são extremamente resistentes. Entretanto, uma vez alterada essa situação (retirada da cobertura vegetal, compactação, movimentação do solo) tornam-se colapsáveis, ocorrendo diversas feições erosivas (Guerra, 1999).

Os Gleissolos ocorrem em áreas mal drenadas, onde ocorre excesso de umidade permanente ou temporária. Restringem-se a porções sujeitas às inundações e às margens de cursos de água. Gleissolos são os intrazonais em que as características zonais não se desenvolveram em virtude da grande influência da água no solo, condicionada principalmente pelo relevo. Apresentam características associadas a encharcamentos, que podem provocar acumulações de matéria orgânica ou um fenômeno de redução identificado pela sua cor típica, correspondendo respectivamente a solos orgânicos e solos mais minerais.

O mapa de suscetibilidade à erosão laminar foi construído a partir do cruzamento entre o mapa pedológico (com as respectivas classes de erodibilidade) e o mapa de declividade (figura 3). O mapa de suscetibilidade à erosão laminar representa os fatores relativos à detecção do potencial erosivo laminar sem os registros de interferência antrópica, sendo estes levantados a partir do conhecimento das formas de ocupação do solo. 
FIGURA 3 - MAPA DE DECLIVIDADE

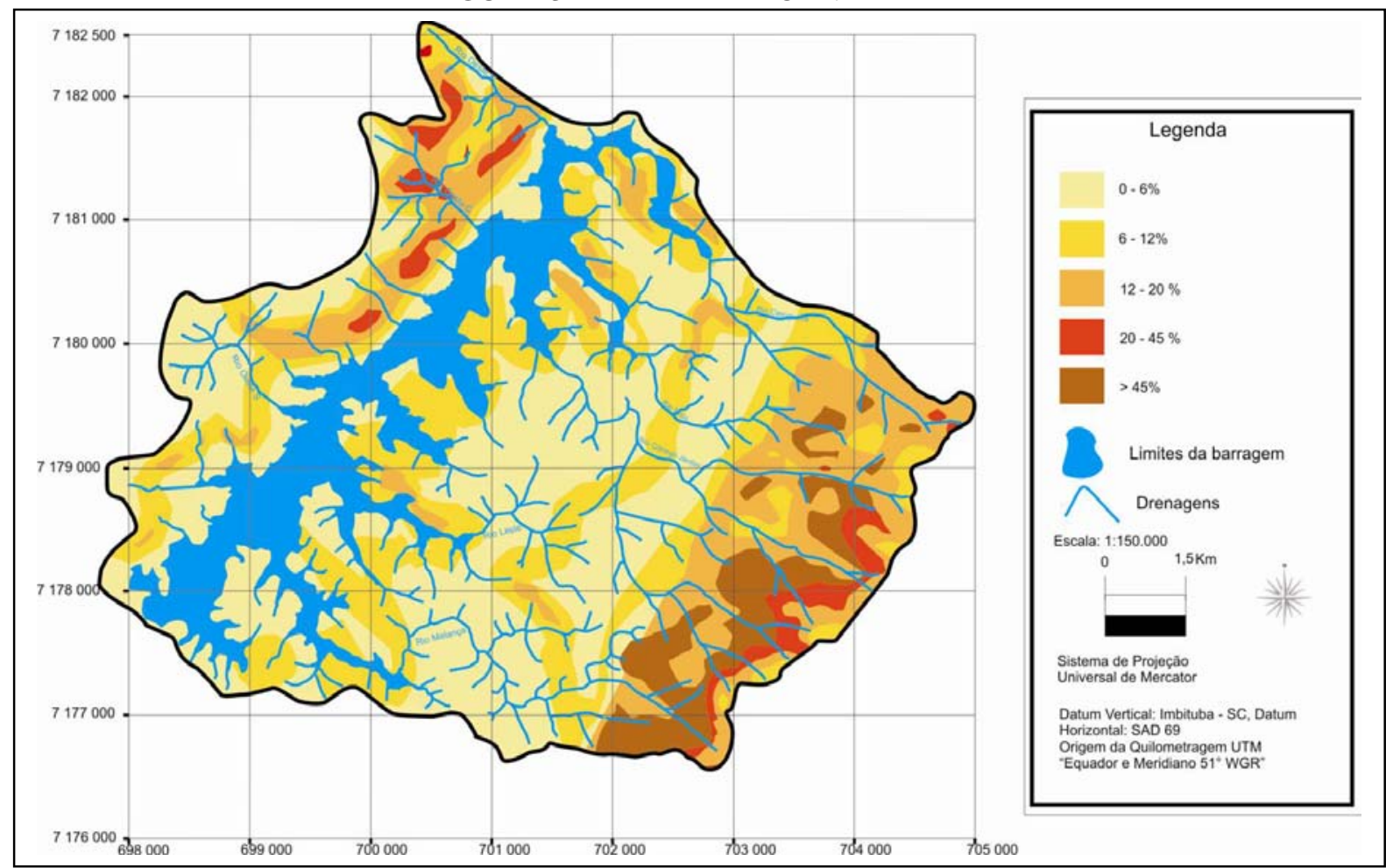

A erodiblidade está fortemente associado com a declividade do terreno para a suscetibilidade dos solos à erosão laminar. O quadro 3 foi adaptado de Guerra (1999) - com base em critérios adotados pelo IPT (1990) - onde o cruzamento destas categorias (declividade e classes de erodibilidade) permitiu definir a seguinte tabela de classes de suscetibilidade à erosão laminar:

QUADRO 3 - CLASSES DE SUSCETIBILIDADE À EROSÃO LAMINAR

\begin{tabular}{|c|c|c|c|c|c|}
\hline & \multicolumn{4}{|c|}{ Mapa de declividade (em \%) } \\
\hline & & $\mathrm{I}(>20)$ & II (12 a 20) & III (6 a 12) & IV $(<6)$ \\
\hline \multirow{4}{*}{$\begin{array}{c}\text { Mapa } \\
\text { pedológico } \\
\text { (com classes } \\
\text { de } \\
\text { erodibilidade) }\end{array}$} & $\begin{array}{c}\text { Classe I } \\
\text { (Cambissolo) }\end{array}$ & I & I & II & II \\
\hline & $\begin{array}{l}\text { Classe II } \\
\text { (Argissolo) }\end{array}$ & I & II & II & III \\
\hline & $\begin{array}{l}\text { Classe III } \\
\text { (Latossolo) }\end{array}$ & III & IV & IV & V \\
\hline & $\begin{array}{l}\text { Classe IV } \\
\text { (Gleissolo) }\end{array}$ & V & v & V & V \\
\hline
\end{tabular}

Fonte: adaptado de Salomão (1994, In: GUERRA et al., 1999). 
As classes definidas, para facilitar a técnica de detecção do potencial à erosão laminar, estão organizadas em ordem decrescente do potencial de suscetibilidade, assim definidas:

a) CLASSE I - extremamente suscetível: os terrenos apresentam problemas complexos de conservação, indicados para preservação ou reflorestamento;

b) CLASSE II - muito suscetível: os terrenos apresentam problemas complexos de conservação, parcialmente favoráveis à ocupação por pastagens, sendo mais apropriados para reflorestamento;

c) CLASSE III - moderadamente suscetível: os terrenos apresentam problemas complexos de conservação, sendo mais indicados a pastagens e culturas perenes;

d) CLASSE IV - pouco suscetível: os terrenos apresentam problemas complexos de conservação, sendo mais indicados a pastagens e culturas perenes e, eventualmente, a culturas anuais, porém exigindo práticas intensivas mecanizadas de controle da erosão;

e) CLASSE V - pouco a não suscetível: corresponde a terrenos sem problemas de conservação, mas exigem técnicas especiais de cultivo, por se constituírem de solos encharcados.

As formas de ocupação do solo interferem excessivamente no potencial à erosão que algumas bacias poderão sofrer. Fica claro, portanto, que o potencial à erosão laminar depende das características naturais do relevo e do solo em função da forma de interferência antrópica desenvolvida. O levantamento da cobertura vegetal e uso do solo (figura 4) encontrados na região foi organizado sob classes (com base no tipo de exposição, atividade desenvolvida e cobertura original), para efetivar o cruzamento de dados na elaboração do mapa potencial à erosão laminar.

Para facilitar o cruzamento com o mapa de uso e ocupação do solo na geração do mapa potencial à erosão laminar, que logo será descrito, estas classes estão organizadas em ordem decrescente de predisposição do solo a processos erosivos, conforme o quadro 4:

QUADRO 4 - CLASSES ADOTADAS PARA O MAPA DE COBERTURA VEGETAL E USO DO SOLO

\begin{tabular}{|c|c|}
\hline Classes de cobertura vegetal e uso do solo & Características \\
\hline I & Solo exposto; \\
\hline II & Culturas (atividades agrícolas); \\
\hline III & Pasto e campos; \\
\hline IV & Cobertura vegetal de porte alto a médio; \\
\hline
\end{tabular}

Fonte: adaptado de Salomão (1994, in: GUERRA et al., 1999) 


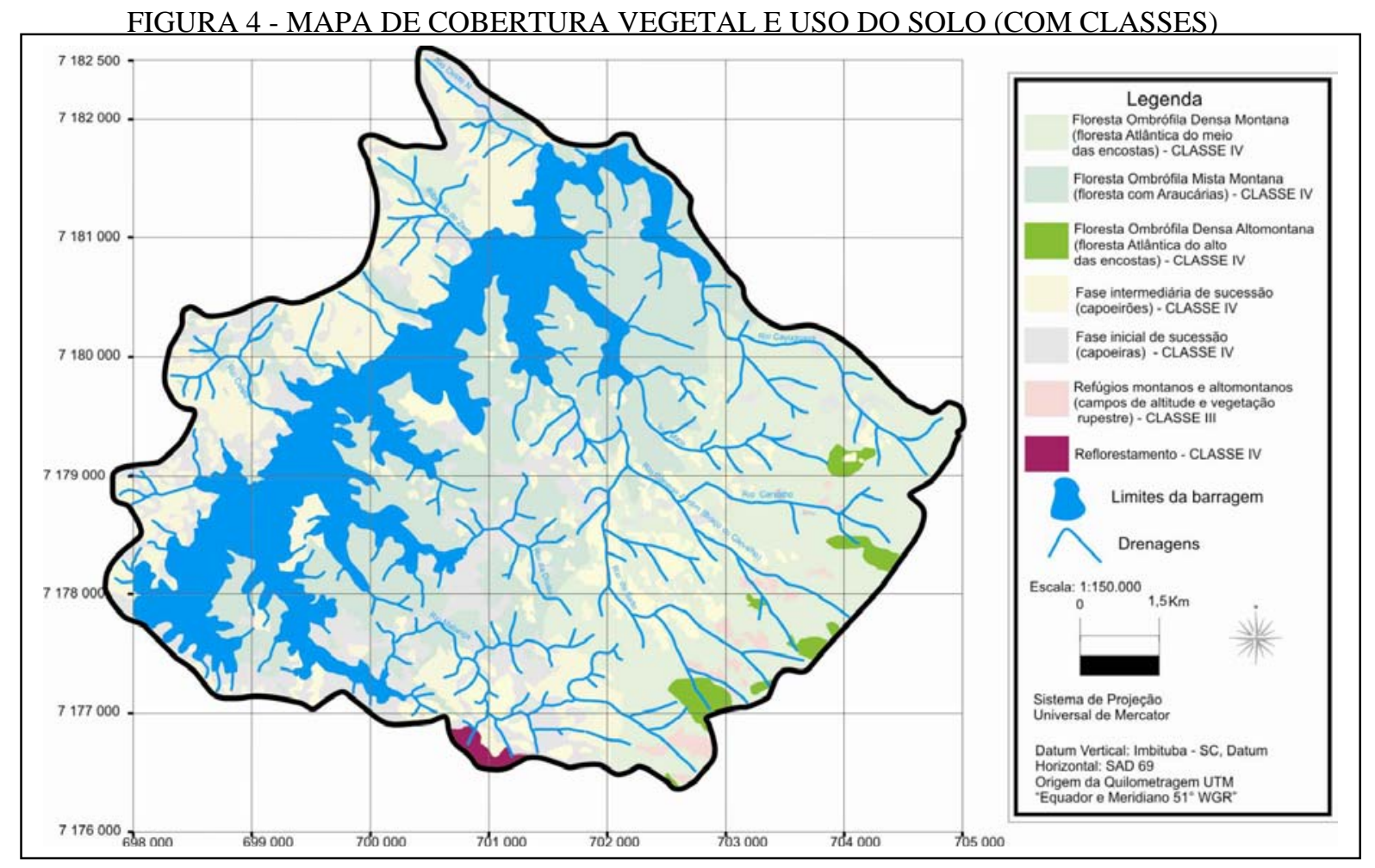

O mapa de potencialidade à erosão laminar foi realizado por meio de um outro tipo de cruzamento, levando em conta a suscetibilidade à erosão laminar e a cobertura vegetal e uso do solo.

O quadro 5 esquematiza os cruzamentos matriciais que geraram o mapa potencial à erosão laminar:

QUADRO 5 - CRUZAMENTO DE CLASSES PARA O MAPA POTENCIAL À EROSÃO LAMINAR

\begin{tabular}{|c|c|c|c|c|c|}
\hline & & \multicolumn{4}{|c|}{ Classes de uso e ocupação dos solos } \\
\hline & & $\begin{array}{c}\text { Solo } \\
\text { exposto } \\
\text { (Classe I) }\end{array}$ & $\begin{array}{l}\text { Culturas - } \\
\text { atividades } \\
\text { agrícolas- } \\
\text { (Classe II) }\end{array}$ & $\begin{array}{c}\text { Pasto e } \\
\text { campos } \\
\text { (Classe III) }\end{array}$ & $\begin{array}{c}\text { Cobertura } \\
\text { vegetal de } \\
\text { porte alto a } \\
\text { médio } \\
\text { (Classe IV) }\end{array}$ \\
\hline \multirow{5}{*}{$\begin{array}{c}\text { Classes } \\
\text { de } \\
\text { susceti- } \\
\text { bilidade } \\
\text { à } \\
\text { erosão } \\
\text { laminar }\end{array}$} & $\begin{array}{c}\text { Extremamente } \\
\text { suscetível (Classe I) }\end{array}$ & I & I & I & II \\
\hline & $\begin{array}{l}\text { Muito suscetível } \\
\text { (Classe II) }\end{array}$ & I & II & II & III \\
\hline & $\begin{array}{c}\text { Moderadamente } \\
\text { suscetível (Classe } \\
\text { III) } \\
\end{array}$ & II & II & II & III \\
\hline & $\begin{array}{l}\text { Pouco suscetível } \\
\text { (Classe IV) }\end{array}$ & II & III & III & III \\
\hline & $\begin{array}{c}\text { Pouco a não } \\
\text { suscetível (Classe } \\
\text { V) }\end{array}$ & III & III & III & III \\
\hline
\end{tabular}

Fonte: adaptado de Salomão (1994, in: GUERRA et al., 1999) 
As classes se apresentam da seguinte maneira:

a) CLASSE I - alto potencial: uso atual do solo incompatível com a suscetibilidade à erosão laminar;

b) CLASSE II - médio potencial: uso atual do solo incompatível com a suscetibilidade à erosão laminar, possível de ser controlada com práticas conservacionistas adequadas;

c) CLASSE III - baixo potencial: uso atual do solo compatível com a suscetibilidade à erosão laminar.

\section{RESULTADOS E DISCUSSÕES}

A partir do conjunto de dados de erodibilidade e declividade, o cruzamento entre estes gerou o mapa de suscetibilidade à erosão laminar (figura 5). Conforme ilustra o gráfico 1, o mapa de suscetibilidade à erosão laminar distribui suas classes da seguinte maneira: classe I $1,79 \mathrm{~km}^{2}$ (8,35 \% da área total), classe II com 4,63 km² (21,59 \%), classe IV apresentando $6,21 \mathrm{~km}^{2}(28,96 \%)$ e classe V com 8,81 km² (41,11 \% da área total).

FIGURA 5 - MAPA DE SUSCETIBILIDADE À EROSÃO LAMINAR

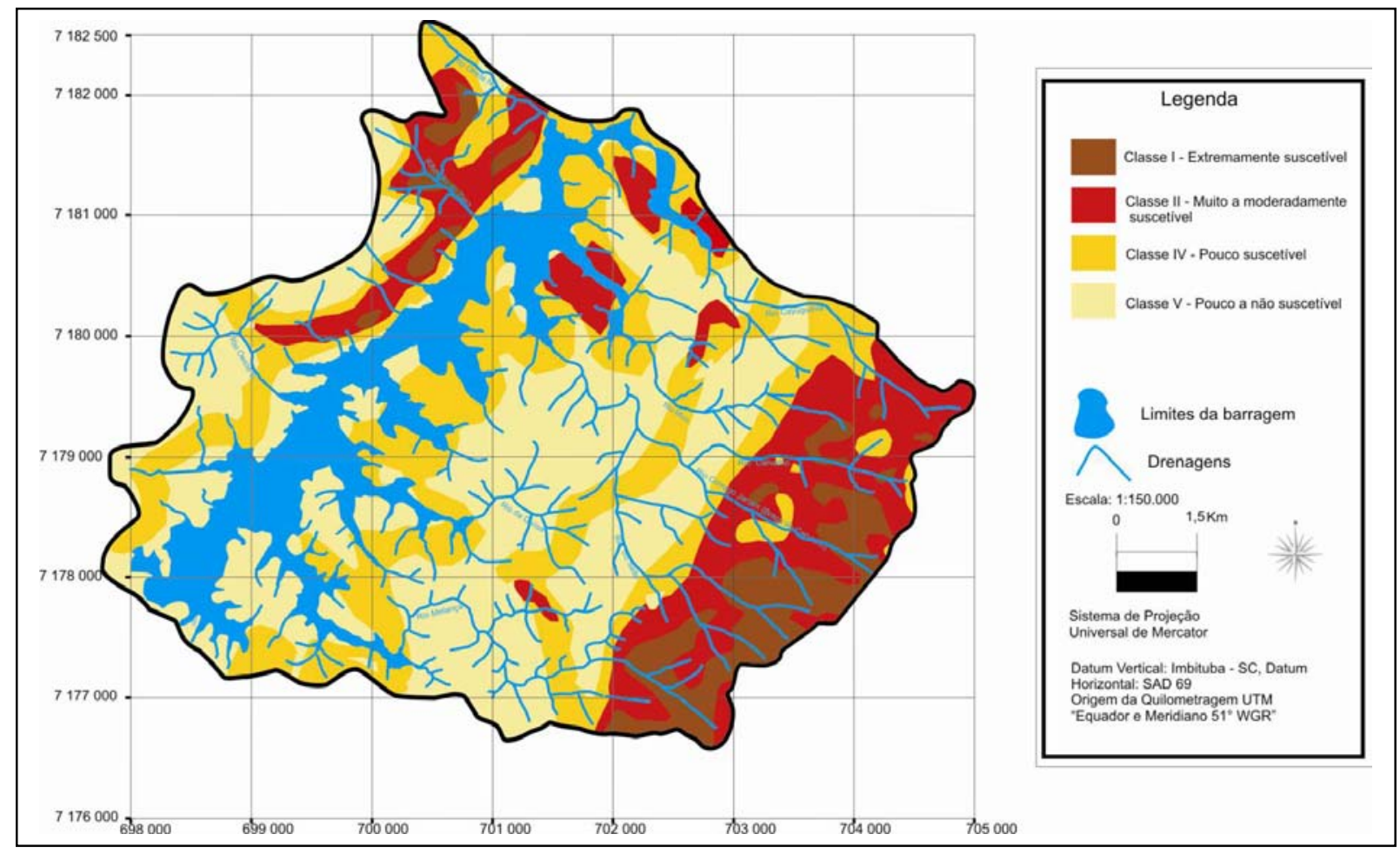




\section{GRÁFICO 1 - DISTRIBUIÇÃO DAS ÁREAS DE CLASSES DE SUSCETIBILIDADE À EROSÃO LAMINAR (\%)}

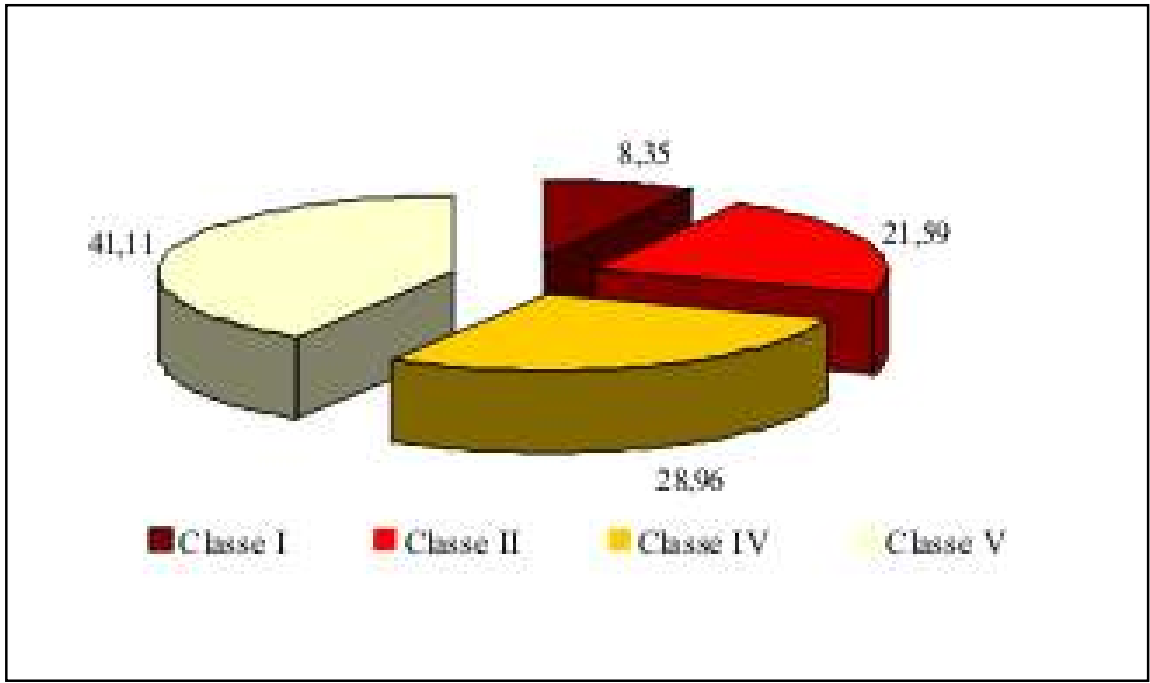

Os levantamentos que permitiram o diagnóstico do mapeamento de potencial erosivo na área de estudo (figura 6) apontaram para a seguinte distribuição das classes de potencial (gráfico 2): classe I - alto potencial - com 0,13 $\mathrm{km}^{2}$ (0,65\% da área total), classe II - médio com $1,78 \mathrm{~km}^{2}$ (ou seja, 8,33\% do total) e classe III - baixo potencial - com 19,52 km² (91,02\%).

\section{FIGURA 6 - MAPA DE POTENCIAIS ÁREAS À EROSÃO LAMINAR}

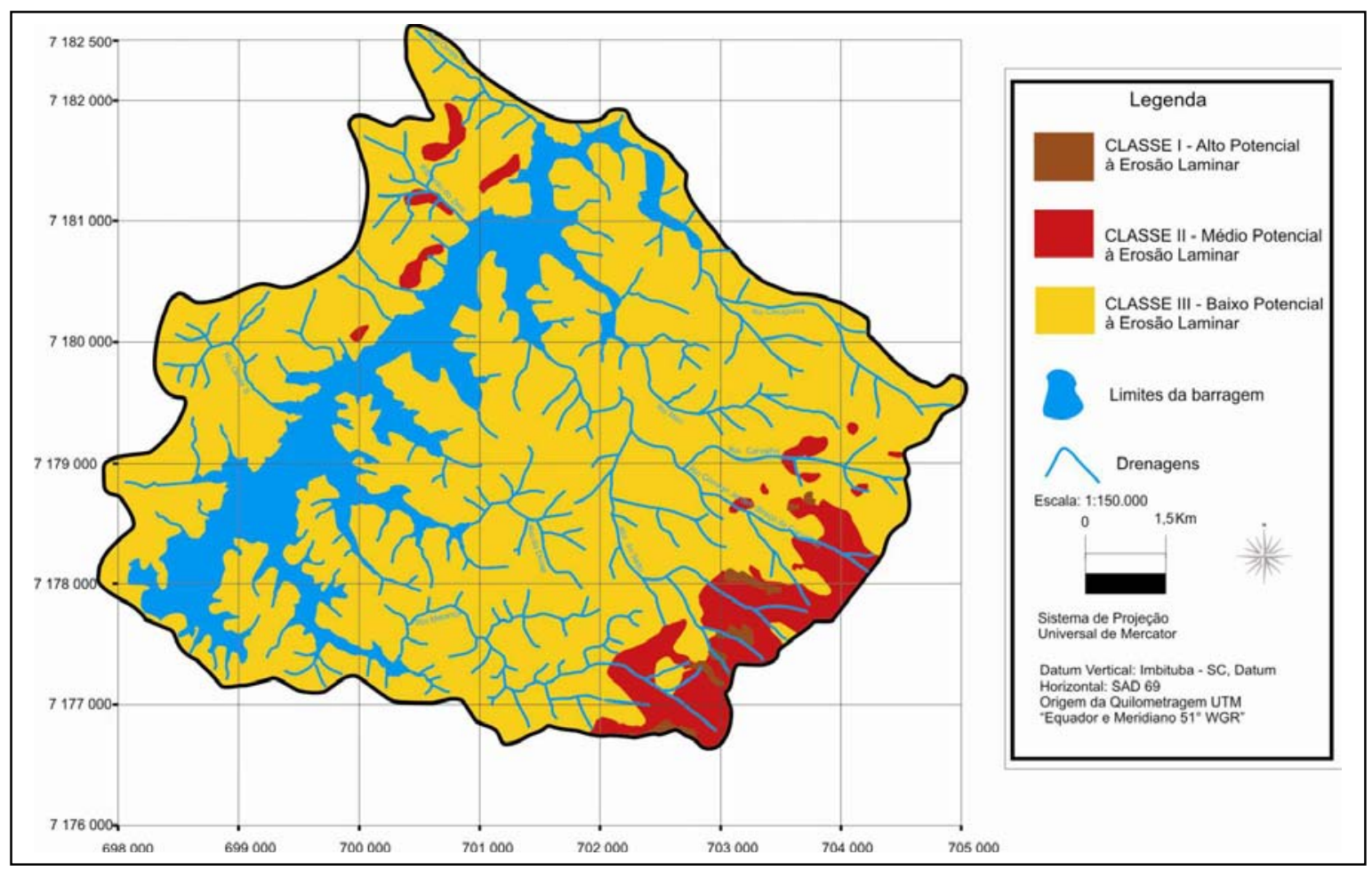




\section{GRÁFICO 2 - DISTRIBUIÇÃO DAS ÁREAS DE CLASSES DE POTENCIALIDADE À EROSÃO}

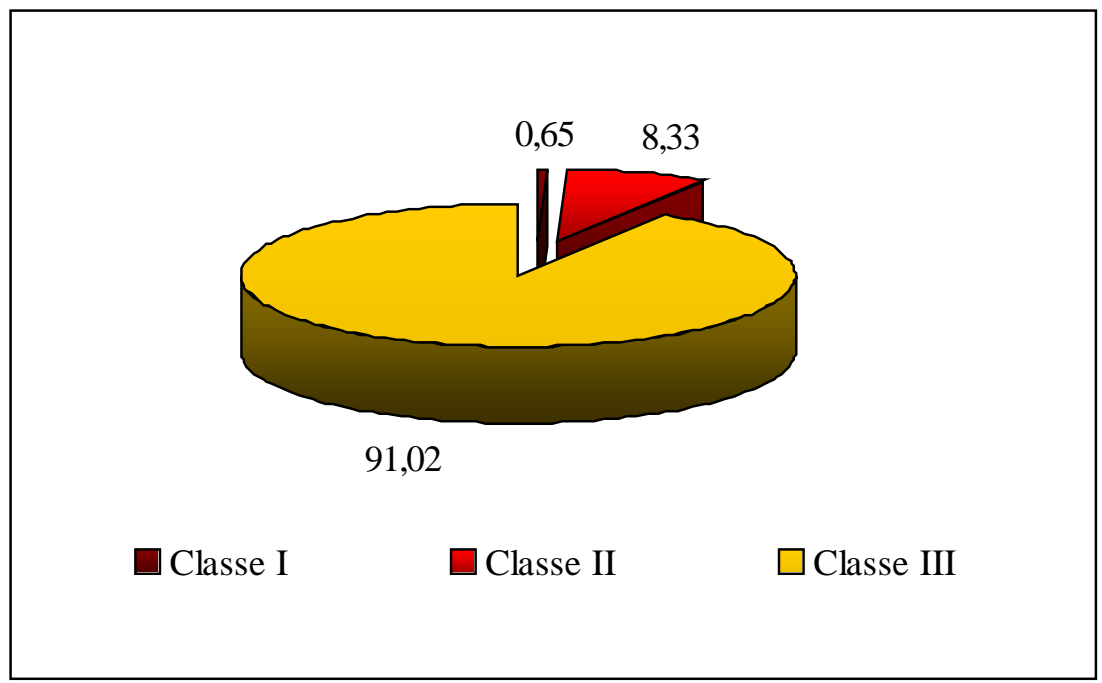

O mapa potencial à erosão laminar mostra que a área de estudo se encontra com pouco potencial à erosão laminar (mais de 99 \% distribuídos entre as classes 2 e 3 (ou seja, áreas de médio e baixo potencial). Este mapa consiste em uma ferramenta importante para a prevenção dos processos erosivos em seus estágios iniciais. Reafirma-se aqui que o potencial erosivo laminar cresce relativamente à medida que o uso e ocupação do solo se faz por meio de práticas como a agricultura (geralmente realizada sem mecanismos de controle) e o crescimento da urbanização. Justamente este último fator mais chama atenção, em função do crescimento urbano do município, fato este vivenciado por praticamente todas as cidades da Região Metropolitana de Curitiba.

Na referida área foi detectada a presença de erosão acentuada em alguns trechos, especialmente em uma trilha de acesso à antiga chaminé da Represa o Carvalho (Prancha 1 figuras 1 e 2), em que observa-se algumas pináculas (torrões) e ravinamento associados (figuras 3 e 4) e o evidente transporte de sedimentos.

Reforça-se o alerta dado por Bustos (2003), em que a ocupação inadequada de uma área de manancial usualmente provoca a destruição das matas ciliares, causando impacto negativo nos processos naturais de manutenção da vida. As diversas formas de ocupação desordenada, bem como o uso inapropriado dos solos para as mais diversas atividades e ainda as específicas condições naturais comprometem a qualidade da água e são responsáveis pelo assoreamento dos corpos de água, afetando o abastecimento da população e, conseqüentemente, reduzindo a qualidade de vida. A existência de altas e médias áreas potenciais à erosão laminar na barragem Piraquara I são fortes indicativos de áreas contribuidoras de sedimentos ao assoreamento. 
PRANCHA 1 - EXEMPLOS DAS FEIÇÕES EROSIVAS ENCONTRADAS

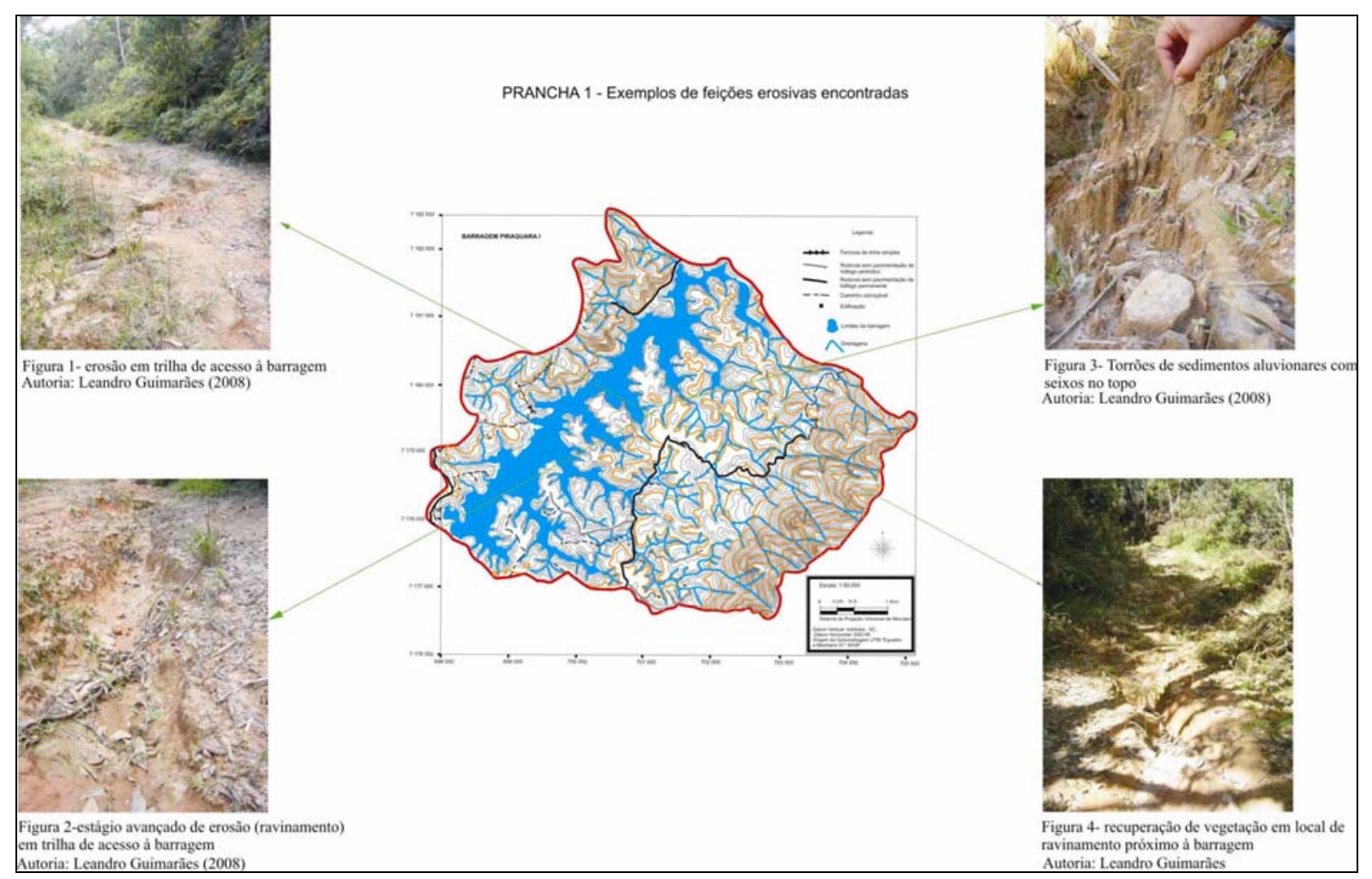

\section{CONSIDERAÇÕES FINAIS}

A partir da metodologia desenvolvida, na elaboração do potencial erosivo laminar, temse como base o indicativo de possíveis áreas-fonte produtoras de sedimentos e também de bacias com escoamento suficiente para que estes sedimentos sejam transportados pelas mesmas para que se depositem na barragem. Em vista disso, o resultado final se direciona ao levantamento de possíveis áreas-fonte ao assoreamento, uma vez que nem sempre todos estes sedimentos serão transportados pelos cursos fluviais das bacias e chegarão à barragem. Uma das principais contribuições deste estudo diz respeito, portanto, a um conhecimento de quais áreas são as que mais alertam para um monitoramento de previsão de impactos (em virtude da potencial produção de sedimentos), realçando que, por ser relativamente antiga, a construção da barragem se deu em uma época em que não era preciso a elaboração do Estudo de Impacto Ambiental e de Relatório de Impacto Ambiental.

A presente área de estudo precisa de monitoramento constante das atividades realizadas para que se evite a expansão da ocupação urbana do município de Piraquara. Cerca de 1,78 $\mathrm{km}^{2}$ (8,33 \% do total) da área da bacia compreende áreas de médio potencial, porém, deve-se 
destacar que a maior concentração urbana de Piraquara está a cerca de $8 \mathrm{~km}$ de distância aproximadamente de áreas de médio potencial (como na porção noroeste da área de estudo). A eventual expansão urbana nestas áreas de médio potencial agravaria a situação, uma vez que a erosão laminar acentua-se a partir deste tipo de uso e ocupação do solo. Por sua vez, a importância das áreas de mananciais recai sobre o abastecimento de água às cidades; o fornecimento de energia elétrica; irrigação de agricultura; pesca e lazer; bem como a proteção às plantas e aos animais. Em geral, os mananciais utilizados para o abastecimento urbano são constituídos pelas cabeceiras de rios, ainda não poluídos, como é o caso de Piraquara I. Além da extrema necessidade de preservação desta barragem por causa de suas características naturais, o monitoramento do turismo ecológico na região e da conscientização já vem sendo feito por alguns grupos preocupados com o futuro de uma das mais belas feições geográficas do nosso Estado.

Reforça-se, por fim, que estudos em barragens sejam voltados também para a detecção das áreas potenciais à produção de sedimentos, com o objetivo, portanto, de lidar com prevenção e não apenas recuperação de danos. Diversos questionamentos são feitos atualmente a respeito da reversibilidade das alterações ambientais causadas pelas diversas atividades humanas no planeta. É fundamental que o ser humano direcione cada vez mais suas idéias para o estudo da prevenção, onde realmente se efetivará o tão aclamado discurso de preservação do nosso planeta para as gerações futuras.

\section{REFERÊNCIAS}

ANDREOLI, C. V.; DALARMI, O.; LARA, A.I.; ANDREOLI, F.N. Limites ao desenvolvimento da Região Metropolitana de Curitiba, impostos pela escassez de água. In: Simpósio Luso-Brasileiro de Engenharia Sanitária e Ambiental, 9., 2000. Anais... Porto Seguro, s. ed., abr. 2000. p.185-195.

CARVALHO, N.O. Assoreamento de reservatórios - conseqüências e mitigação dos efeitos. In: Encontro Nacional de engenharia de Sedimentos, 4, 2000. Santa Maria. Cd rom. 1. 2000.

CARVALHO, N.O. Hidrossedimentologia prática. Rio de Janeiro: CPRM e ELETROBRÁS, 1994. 
CARVAlHO, N.O. et al. Causas e Efeitos do Aumento da Produção de Sedimentos na Bacia Hidrográfica do Tocantins-Araguaia. In: Congresso Regional do Centrooeste de Recursos Hídricos, 2002, Campo Grande. CD-ROM.

COIADO, E. M. Assoreamento de Reservatórios. In: Paiva J.B.D.; Paiva E.M.C.D. (Orgs.). Hidrologia Aplicada à Gestão de Pequenas Bacias Hidrográficas. Porto Alegre: ABRH, 2001. p.395.

DIAS, N. W.; BATISTA, G. T.; TARGA, M. dos S.; CATELANI, C. de S. Análise da carga de sedimentos da Represa de Paraibuna com base em dados multiespectrais. In: Simpósio Brasileiro de Recursos Hídricos, 16., 2005, João Pessoa. Anais... 2005.

DIBIESO, E. P.; LEAL, A. C. Análise morfométrica da drenagem da bacia hidrográfica do córrego do Cedro - Presidente Prudente/SP. In: Semana de Geografia, 6., 2005, Presidente Prudente.

GUERRA, A. J. T.; SILVA, A. S.; BOTELHO, R. G. M. (Org.). Erosão e conservação dos solos: conceitos, técnicas e aplicações. Rio de Janeiro: Bertrand Brasil, 1999.

INSTITUTO DE PESQUISAS TECNOLÓGICAS DO ESTADO DE SÃO PAULO - IPT. Orientações para o combate à erosão no estado de São Paulo: Bacia do Pardo Grande. São Paulo: 1990, v.3.

JENNY, H. Factors of soil formation. New York: McGraw-Hill Book Company, Inc., 1941.

LIMA, M. C. Fragilidade ambiental da Bacia do Rio Pacatuba. Curitiba, 2004. Monografia (Especialização em Geografia). Setor de Ciências da Terra, Universidade Federal do Paraná.

MORRIS, G. L; FAN, J. Reservoir sedimentation handbook. New York: Mcgraw-HILL, 1997.

OLIVEIRA, A. M. dos S. Depósitos tecnogênicos e assoreamento de reservatórios. Exemplo do reservatório de capivara, Rio Paranapanema, SP/PR. São Paulo, 1994, 204 p. Tese (Doutorado em Geografia Física) - Departamento de Geografia da Faculdade de Filosofia, Letras e Ciências Humanas, Universidade de São Paulo.

PREFEITURA MUNICIPAL DE PIRAQUARA. Prefeito destaca acordo em explosão no canteiro de obras da barragem do Piraquara II. Agência de Notícias, Piraquara, 23 mar. 
2006. Disponível em: <http://www.piraquara.pr.gov.br/noticias/index.php?not=325> Acesso em: 25 set. 2007.

SALOMÃO, F. X. DE T. Processos erosivos lineares em Bauru: regionalização cartográfica aplicada ao controle preventivo urbano e rural. São Paulo, 1994. 200 p. Tese. (Doutorado em Geografia Física) - Departamento de Geografia da Faculdade de Filosofia, Letras e Ciências Humanas, Universidade de São Paulo.

SILVA, S. A. Avaliação do assoreamento do lago Bonsucesso, Jataí-GO. Curitiba, 2007. Dissertação (Mestrado em Geologia) - Setor de Ciências da Terra, Universidade Federal do Paraná.

STRAHLER, A. N. Geografia Física. Barcelona: Omega, 1997.

TONELLO K. C.; DIAS, H. C. T.; SOUZA, A. L. de; RIBEIRO, A. A. S. e LEITE, F. P Morfometria da bacia hidrográfica da Cachoeira das Pombas, Guanhães - MG. Revista Árvore, Viçosa, v. 30, n. 5, p. 849-857, set.out. 2006.

VILLELA, S. M.; MATTOS, A. Hidrologia aplicada. São Paulo: McGraw-Hill do Brasil, 1975. 